\title{
Complexity Dynamic Character Analysis of Retailers Based on the Share of Stochastic Demand and Service
}

\author{
Junhai Ma, Weiya Di, and Hao Ren \\ College of Management and Economics, Tianjin University, Tianjin 300072, China \\ Correspondence should be addressed to Weiya Di; weiyd140612@126.com and Hao Ren; hren20161028@126.com
}

Received 27 March 2017; Revised 12 May 2017; Accepted 22 May 2017; Published 24 September 2017

Academic Editor: Sajad Jafari

Copyright (C) 2017 Junhai Ma et al. This is an open access article distributed under the Creative Commons Attribution License, which permits unrestricted use, distribution, and reproduction in any medium, provided the original work is properly cited.

\begin{abstract}
Apart from the price fluctuation, the retailers' service level becomes another key factor that affects the market demand. This paper depicts a modified price and demand game model based on the stochastic demand and the retailer's service level which influences the market demand decided by customers' preference, while the market demand is stochastic in this model. We explore how the price adjustment speed affects the stability of the supply chain system with respect to service level and stochastic demand. The dynamic behavior of the system is researched by simulation and the stability domain and the bifurcation phenomenon are shown clearly. The largest Lyapunov exponent and the chaotic attractor are also given to confirm the chaotic characteristic of the system. The simulation results indicate that relatively small price adjustment speed may maintain the system at stable state. With the price adjustment speed gradually increasing, the price system gets unstable and finally becomes chaotic. This chaotic phenomenon will perturb the product market and this phenomenon should be controlled to keep the system stay in the stable region. So the chaos control is done and the chaos can be controlled completely. The conclusion makes significant contribution to the system referring to the price fluctuation based on the service level and stochastic demand.
\end{abstract}

\section{Introduction}

Bertrand duopoly model is frequently used when the competitive behaviors are discussed in proper research. Hence, the dynamic behaviors of the whole supply chain system have already been probed. However, the retail service level plays an important role in influencing the retail price which indirectly changes the dynamic behaviors of the whole supply chain system that contains one supplier and two retailers.

The two retailers are duopoly in the product market. Xiao and Yang [1] established a price-service competition model with the circumstance whereby the demand is uncertainty in two competing supply chains considering the risk sensitivity. The outcome showed the higher service investment efficiency of one retailer may lead to lower optimal price and service level of his rival. Yan and Pei [2] focused on the retail service in a dual-channel supply chain, while the result suggested that the improved retail services enhanced the supply chain performance effectively in a dual-channel supply chain. Hall et al. [3] engaged in the dynamic retail price and ordering decisions in the category management setting, and this research found brand's own price and the crossprice effect had an effect on the brand-by-brand market. Ghosh and Mitra [4] examined the different and opposite results to the ones obtained from a similar comparison in the standard setting through comparing the Bertrand and Cournot model in mixed markets with public and private enterprises considering maximum welfare and maximum profit separately.

C. H. Tremblay and V. J. Tremblay [5] introduced a Cournot-Bertrand duopoly model in a Cournot-type firm and a Bertrand-type firm based on the degree of product differentiation. The Cournot-Bertrand equilibrium was calculated and the analysis of the equilibrium was also conducted. Sieke et al. [6] investigated the service level based supply contracts including flat penalty contract and unit penalty contract in a coordinated supply chain. The optimal values of the contract parameters were decided and service level measures were connected to traditional service level measures. Ma and Zhang [7] analyzed the property of three oligarchs which have different rationalities in insurance market based on the price game model and variable feedback 
control method. Naimzada and Tramontana [8] studied the liner demand and cost functions with product differentiation, and a dynamic model was established to probe into the stability properties in the mixed Cournot-Bertrand duopoly model. Elsadany [9] developed a triopoly game to indicate the characteristic of a dynamic Cournot game through three bounded rational players. Jha and Shanker [10] introduced the circumstance where a supplier produced products and supplied them to a set of buyers. The lead time can be reduced with an added cash cost and a service level constraint was also included in the research. Wang and Ma [11] centered on the limited information in a Cournot-Bertrand mixed duopoly game model. The bounded rational principles were used to help the two firms make management decisions. He discussed the Nash equilibrium point and the local stability of the game. Mahmoodi and Eshghi [12] added the price competition and the stochastic demand into the duopoly supply chains; the effect of price and the uncertainty demand on the system were discussed.

Ahmed et al. [13] pointed out that the gradient adjustment mechanism of price was applied in a dynamic Bertrand duopoly in which the goods were differentiated. Kawabata and Takarada [14] probed into the effect of free trade agreements on the welfare in Bertrand and Cournot competition model under differentiated products. Brianzoni et al. [15] studied the mathematical properties and dynamics of a Bertrand duopoly with horizontal differentiated products and nonlinear costs, and the new evidence has been offered. Liu and Wang [16] investigated the quality control game that discussed the different risk attitudes affecting quality control game of supply chain especially in logistics service supply chain, instead of considering one member's risk attitude and ignoring the combination of two members' risk attitudes. Fang and Shou [17] managed supply uncertainty under supply chain Cournot competition between two supply chains consisting of a retailer and an exclusive supplier, respectively.

Esmaeilzadeh and Taleizadeh [18] conducted the optimal pricing decisions for two complementary products in a twoechelon supply chain under different market powers with game theory approaches. Ma and Guo [19] examined the impacts of information on the dynamical price game in two Bertrand game models, whereby the player obtains information of his rival before making decisions. Q.-H. Li and $\mathrm{B}$. Li [20] designed the dual-channel supply chain; thus channel competition became inevitable. Hence, value-added services provided by retailers were considered. Equilibrium problems regarding retail services and fairness concerns were analyzed. Protopappa-Sieke et al. [21] developed the optimal two-period inventory allocation policies under multiple service level contracts in view of the fact that optimal inventory allocation had a significant impact on profits in the retail industry. How a manufacturer responds to a service level contract was analyzed as considering to minimize the expected costs.

The structure of the paper is as follows. Firstly, the basic Bertrand duopoly model considering the service level and stochastic demand is established in Section 2. Secondly, the analysis of the model mentioned in the above section has been conducted in Section 3. Then, we simulate the stability domain and the dynamical behaviors, and the related discussions have been made in Section 4. Lastly, the conclusion will be given in Section 5 .

\section{Demand Model}

Since oligopoly game model has already been researched in previous literature, while the oligopoly situation has been discussed, we consider that the other retailer comes into the monopoly market. Due to the entrance of the other retailer, exclusive monopoly was broken. What is more, the marketing competition is more vehement. Retailer's demand is influenced by the other retailer's price. In addition to retail price, we also consider that the market demand is associated with the service level of themselves and the competitors. Meanwhile, we assume the products that two retailers sell are homogeneous. Hence, the demand function of the two retailers is shown as follows:

$$
\begin{aligned}
& d_{1}=a_{1}-b_{1} p_{1}+b_{2} p_{2}+k_{1} v_{1}-k_{2} v_{2}, \\
& d_{2}=a_{2}-b_{1} p_{2}+b_{2} p_{1}+k_{1} v_{2}-k_{2} v_{1},
\end{aligned}
$$

where $k_{i}(i=1,2)$ shows the ratio of customers buying the product, which represents the service discrepancy level of the products. $b_{i}(i=1,2)$ represents the price sensitive coefficient, which expresses the degree of market demand influenced by the price of their products and competition's product price. Due to the difference of the price and service level between two products, customers will make their own choice according to the price and service level. We must be clear that the higher the service level of the products is, the more the consumers will choose to buy the products in condition of the same price level facing the homogeneous product.

In the expression above, we find that the market demand is affected by both retail price and the service level. The higher service level will bring about the larger cost. The cost of service level is shown in

$$
c_{i}=\eta_{i} \frac{v_{i}^{2}}{2}, \quad i=1,2 .
$$

In (2), $v_{i}$ means the service level of two retailers. $\eta_{i}$ is the influence coefficient, which is used to signify the influence degree of the service level to cost.

While the product market is complex and stochastic, the final demand of the customers is uncertain. We set the demand as stochastic variable $a_{i}$, whereby the stochastic demand is the sum of the fixed demand $a_{i, 0}$ and the potential stochastic part with market uncertainty $e$, that is, $a_{i}=$ $a_{i, 0}+e$. And the expectation and variance of $e$ are 0 and $r$, respectively. We assume that retailers can predict the stochastic demand of their products. Retailers can help to make decisions with the market information forecast, when facing the uncertain factors in the product market. The forecast value of the stochastic demand is $f$, and $f$ is composed with stochastic variable $a_{i}$ and the error term $\varepsilon$, that is, $f_{i}=a_{i}+\varepsilon$. The expectation and variance of $\varepsilon$ are 0 and $s$, 
separately. We have to point out that $e$ and $s$ are independent. Just like the former research that in $\mathrm{Li}$ [22], we know

$$
\begin{aligned}
E\left(a_{i} f\right) & =\frac{s_{i}}{r_{i}+s_{i}} a_{i, 0}+\frac{r_{i}}{r_{i}+s_{i}} f_{i}, \\
E\left(\left(f-a_{i, 0}\right)^{2}\right) & =r+s .
\end{aligned}
$$

The profit function of the manufacturer is depicted in (4). In this equation, $w$ represents the wholesale prices that manufacturer sells the products to retailer:

$$
\pi_{m}=\left(d_{1}+d_{2}\right) w .
$$

The retailers' operating goal is to maximize profits. The retailer's profit function is shown as follows:

$$
\pi_{R, i}=\left(p_{i}-w-c_{i}\right) d_{i}, \quad i=1,2 .
$$

When retailers and manufacturer in the market share the information, the expected profits decision models of manufacturer and retailers are shown as follows, respectively:

$$
\begin{aligned}
\max E\left(\pi_{m}^{i s}\right) & =\left(d_{1}+d_{2}\right) w, \\
\max E\left(\pi_{R, 1}^{i s}\right) & =\left[\left(p_{1}-w-c_{1}\right) f_{1} d_{1}\right], \\
\max E\left(\pi_{R, 2}^{i s}\right) & =\left[\left(p_{2}-w-c_{2}\right) f_{2} d_{2}\right] .
\end{aligned}
$$

We can deduce the marginal profits of two retailers through calculating the first-order partial derivative of (6):

$$
\begin{aligned}
\frac{\partial E\left(\pi_{R, 1}^{N I}\right)}{\partial p_{1}}= & \left(1-g_{1}\right) a_{0,1}+g_{1} f_{1}-2 b_{1} p_{1}+b_{2} p_{2} \\
& +k_{1} v_{1}-k_{2} v_{2}+b_{1} w+b_{1} \eta_{1} \frac{v_{1}^{2}}{2} \\
\frac{\partial E\left(\pi_{R, 2}^{N I}\right)}{\partial p_{2}}= & \left(1-g_{2}\right) a_{0,2}+g_{2} f_{2}-2 b_{1} p_{2}+b_{2} p_{1} \\
& +k_{1} v_{2}-k_{2} v_{1}+b_{1} w+b_{1} \eta_{2} \frac{v_{2}^{2}}{2} .
\end{aligned}
$$

For the sake of simplicity, we make $g_{i}=r_{i} /\left(r_{i}+s_{i}\right)(i=$ $1,2)$ in $(7)$.

2.1. Optimal Decision. If there is only one retailer in the market, the retailer regards profit maximization as the goal to give the optimal decision in the circumstance of discrete game. When there are two retailers in the market, the optimal decision of retailer 1 is influenced by retailer 2. Meanwhile, retailer 2 optimal decision is also affected by retailer 1 decision. Hence, we assume the information in the market can be shared between two retailers; that is, the optimal decisions of two retailers are known to each other. When the marginal profits reduce to zero, we have the optimal decision for retailers. The retail price and the service level are the decision variables.
For retailer 1, we calculate the first-order derivative of its profit. When the marginal profit gets to zero, the optimal retail price and optimal service level will be derived in equation. The detailed process is as follows:

$$
\begin{aligned}
& \frac{\partial E\left(\pi_{R, 1}^{N I}\right)}{\partial p_{1}}=0, \\
& \frac{\partial E\left(\pi_{R, 1}^{N I}\right)}{\partial V_{1}}=0, \\
& p_{1}^{i s}=\frac{1}{2 b_{1}}\left(\left(1-g_{1}\right) a_{0,1}+g_{1} f_{1}+b_{2} p_{2}-k_{2} v_{2}+b_{1} w\right. \\
& \left.\quad+\frac{3 k_{1}^{2}}{2 \eta_{1} b_{1}}\right), \\
& v_{1}^{i s}=\frac{k_{1}}{b_{1} \eta_{1}} .
\end{aligned}
$$

Analogously, the optimal decision of retailer 2 will be conducted. Equation (10) has the same meaning as (8). The optimal decision of retailer 2 is expressed in (11):

$$
\begin{aligned}
& \frac{\partial E\left(\pi_{R, 2}^{N I}\right)}{\partial p_{2}}=0, \\
& \frac{\partial E\left(\pi_{R, 2}^{N I}\right)}{\partial V_{2}}=0, \\
& p_{2}^{i s}=\frac{1}{2 b_{1}}\left(\left(1-g_{2}\right) a_{0,2}+g_{2} f_{2}+b_{2} p_{1}-k_{2} v_{1}+b_{1} w\right. \\
& \left.\quad+\frac{3 k_{1}^{2}}{2 \eta_{2} b_{1}}\right), \\
& v_{2}^{i s}=\frac{k_{1}}{b_{1} \eta_{2}} .
\end{aligned}
$$

When two retailers make their own optimal decision, we may further find the second derivatives of the retail prices and service level are less than zero. Therefore, the optimal decision of the system will be derived, which means the system has the equilibrium point: $p_{1}^{*}, p_{2}^{*}, v_{1}^{*}, v_{2}^{*}$. The calculation will be expressed as follows:

$$
\begin{aligned}
& \frac{\partial^{2} E\left(\pi_{R, 1}^{N I}\right)}{\partial^{2} p_{1}}<0, \\
& \frac{\partial^{2} E\left(\pi_{R, 1}^{N I}\right)}{\partial^{2} V_{1}}<0, \\
& \frac{\partial^{2} E\left(\pi_{R, 2}^{N I}\right)}{\partial^{2} p_{2}}<0, \\
& \frac{\partial^{2} E\left(\pi_{R, 2}^{N I}\right)}{\partial^{2} V_{2}}<0 .
\end{aligned}
$$


Through jointing (9) and (11), the optimal solution of the system will be solved:

$$
\begin{aligned}
& p_{1}^{*}=\frac{2 b_{1}}{4 b_{1}^{2}-b_{2}^{2}}\left(R_{1}+\frac{b_{2}}{2 b_{1}} R_{2}+\frac{b_{2}}{2 b_{1}} B+A\right), \\
& p_{2}^{*}=\frac{2 b_{1}}{4 b_{1}^{2}-b_{2}^{2}}\left(R_{2}+\frac{b_{2}}{2 b_{1}} R_{1}+\frac{b_{2}}{2 b_{1}} A+B\right), \\
& v_{1}^{*}=\frac{k_{1}}{b_{1} \eta_{1}}, \\
& v_{2}^{*}=\frac{k_{1}}{b_{1} \eta_{2}} .
\end{aligned}
$$

In (13), we have $R_{1}=\left(1-g_{1}\right) a_{0,1}+g_{1} f_{1}, R_{2}=\left(1-g_{2}\right) a_{0,2}+$ $g_{2} f_{2}, A=b_{1} w+k_{1}\left(3 k_{1} \eta_{2}-k_{2} \eta_{1}\right) / b_{1} \eta_{1} \eta_{2}, B=b_{1} w+k_{1}\left(3 k_{1} \eta_{1}-\right.$ $\left.k_{2} \eta_{2}\right) / b_{1} \eta_{1} \eta_{2}$

2.2. The Complex Dynamics of the System. Due to the complexity of the product market, the competition between enterprises in the market is increasingly fierce. Retailers do not know the perfect information of the market, while the market is complex and customers' demands are uncertain. In addition, the more the transactions are, the greater the uncertainty will be, the more incomplete the information will be. Hence, the market demand cannot be forecasted accurately. The bounded rationality expectations solve this problem faultlessly. The retail price of next period will be decided according to the retail price in this period and the marginal profits, which makes up the discrete dynamic system of the product market.

$$
\begin{array}{r}
p_{1}(t+1)=p_{1}(t)+\theta_{1} p_{1}(t)\left(\left(1-g_{1}\right) a_{0,1}+g_{1} f_{1}\right. \\
\left.-2 b_{1} p_{1}+b_{2} p_{2}+k_{1} v_{1}-k_{2} v_{2}+b_{1} w+b_{1} \eta_{1} \frac{v_{1}^{2}}{2}\right), \\
p_{2}(t+1)=p_{2}(t)+\theta_{2} p_{2}(t)\left(\left(1-g_{2}\right) a_{0,2}+g_{2} f_{2}\right. \\
\left.-2 b_{1} p_{2}+b_{2} p_{1}+k_{1} v_{2}-k_{2} v_{1}+b_{1} w+b_{1} \eta_{2} \frac{v_{2}^{2}}{2}\right) .
\end{array}
$$

In the equation above, $\theta_{i}(i=1,2)$ is the price adjustment speed of retailer $i$, and the price adjustment speed is positive, which is set to make sure that retail price of next period is practically significant. When the marginal profit takes positive value, the retail price of next period will increase. However, when the marginal profit takes negative value, the retail price of next period will decrease.

The system (14) is nonlinear; the system is running under constant interference. When the system is disturbed, whether it can maintain a predetermined trajectory, the stability of the system becomes the primary question to study. What is different from the linear system is that the nonlinear system has multiple equilibriums. We obtain four equilibriums of system (14): $E_{0}(0,0), E_{1}\left(0,\left(R_{2}+B\right) / 2 b_{1}\right), E_{2}\left(\left(R_{1}+A\right) / 2 b_{1}, 0\right)$,
$E^{*}\left(\left(2 b_{1} /\left(4 b_{1}^{2}-b_{2}^{2}\right)\right)\left(R_{1}+\left(b_{2} / 2 b_{1}\right) R_{2}+\left(b_{2} / 2 b_{1}\right) B+A\right),\left(2 b_{1} /\left(4 b_{1}^{2}-\right.\right.\right.$ $\left.\left.\left.b_{2}^{2}\right)\right)\left(R_{2}+\left(b_{2} / 2 b_{1}\right) R_{1}+\left(b_{2} / 2 b_{1}\right) A+B\right)\right)$.

We may find that $E_{0}, E_{1}, E_{2}$ are boundary points, and $E^{*}$ is within the system. We guess that $E^{*}$ is the unique Nash equilibrium. In order to verify the guess and analyze the stability of the system, we calculate the Jacobian matrix of system (14):

$$
J(E)=\left(\begin{array}{ll}
J_{11} & J_{12} \\
J_{21} & J_{22}
\end{array}\right) .
$$

In the equation above,

$$
\begin{aligned}
& J_{11}=1+\theta_{1} R_{1}+\theta_{1} b_{2} p_{2}+\theta_{1} A-4 \theta_{1} b_{1} p_{1} \\
& J_{12}=\theta_{1} b_{2} p_{1} \\
& J_{21}=\theta_{2} b_{2} p_{2} \\
& J_{22}=1+\theta_{2} R_{2}+\theta_{1} b_{2} p_{1}+\theta_{2} B-4 \theta_{2} b_{1} p .
\end{aligned}
$$

$E^{*}$ is the unique Nash equilibrium; the best profit of the system can be obtained when the best decision is in $E^{*}$. We all know that when the margin profit is more than zero, the retailers will adjust their retail prices, until the margin profit goes up to zero. At this time, the system reaches to equilibrium state. Retailers will not change their own retail price any more, and the equilibrium state will be maintained by these two game players. Therefore, among all the equilibrium points, only the Nash equilibrium $E^{*}$ has practical significance. Then, this part will explore the local stability of the Nash equilibrium by using the Jacobian matrix and the July criterion.

The characteristic polynomial of the Jacobian matrix takes the following form:

$$
F(\lambda)=\lambda^{2}-\left(J_{11}+J_{22}\right) \lambda-\left(J_{11} J_{22}-J_{12} J_{21}\right) .
$$

In order to guarantee that the Nash equilibrium is local stability, $J_{i, j}(i, j=1,2)$ must satisfy the following limitations:

$$
\begin{array}{r}
-\left(J_{11}+J_{22}\right)+\left(J_{11} J_{22}-J_{12} J_{21}\right)+1>0, \\
\left(J_{11}+J_{22}\right)+\left(J_{11} J_{22}-J_{12} J_{21}\right)+1>0, \\
J_{11} J_{22}-J_{12} J_{21}<1, \\
J_{11}+J_{22}>0 .
\end{array}
$$

Due to the fact that limitations are so complex, the process to solve inequality (18) is very complicated. If the Nash equilibrium satisfies inequality (18), we may insure that Nash equilibrium is locally stable. We will probe into the dynamic characteristic of the system through numerical simulation in next section.

\section{Dynamic Characteristics of the System}

In consideration of the complexity of system (14), the numerical simulation method will be employed in this paper as this method has been widely used in most of the literatures. 


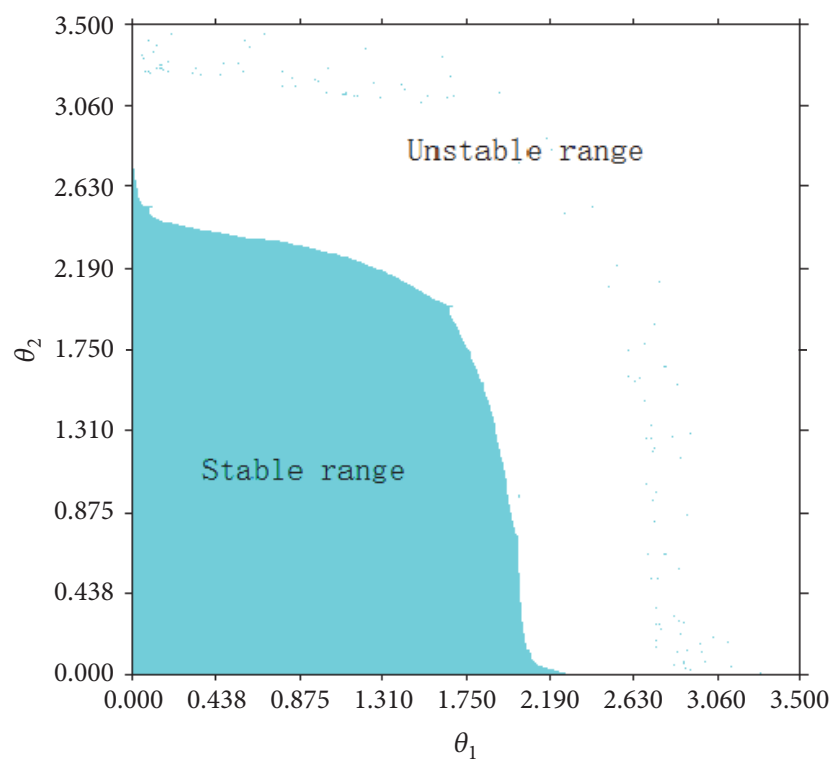

Figure 1: The stable range of system (14).

The stable region, bifurcation, and chaos will be investigated; meanwhile, the largest Lyapunov exponent, entropy, chaotic attractor, and the time domain response will be discussed to verify the dynamic characteristics of this system. At last, the sensitivity of initial value will be analyzed. We take the parameter values as follows: $g_{1}=0.7, g_{2}=0.6, a_{0,1}=0.5$, $a_{0,2}=0.55, f_{1}=0.6, f_{2}=0.65, b_{1}=1, b_{2}=0.5, k_{1}=1.1$, $k_{2}=1.2, v_{1}=0.7, v_{2}=0.6, w=0.1, \eta_{1}=0.2, \eta_{2}=0.3$.

3.1. The Stable Region. The decision variables of the system are retail prices of two retailers. As retail prices obtain different values, the system will change to either the stable range or the unstable range. Figure 1 depicts the stable region of the system with blue range and the unstable of the system with white region. When employed values are in the blue range, the system will tend to the equilibrium state after iteration period by period. Then the system will stay at the Nash equilibrium state unless some factors outside break the equilibrium state.

3.2. The Bifurcation and Chaos Behavior. The fixed point is stable when all the eigenvalues of the Jacobian are in the unit circle. When $\theta_{1}$ and $\theta_{2}$ satisfy the critical value, the system appears as saddle point. If one characteristic root $\lambda_{2}=-1$ and all the other eigenvalues are within the unit circle, the fixed point will be unstable and produce period-doubling bifurcation. From Figure 2, we can see that system (14) will appear as period-doubling bifurcation.

We discuss the bifurcation and chaos behaviors of the system in this section with parameter basin plots and the bifurcation diagram. We set the initial values of the system as $p_{1}(0)=0.25$ and $p_{2}(0)=0.2$, which represent the retail price of two retailers at the first moment.

Figure 3 describes the parameter basin plots of system (14) with respect to the price adjustment speeds $\theta_{1}$ and $\theta_{2}$.

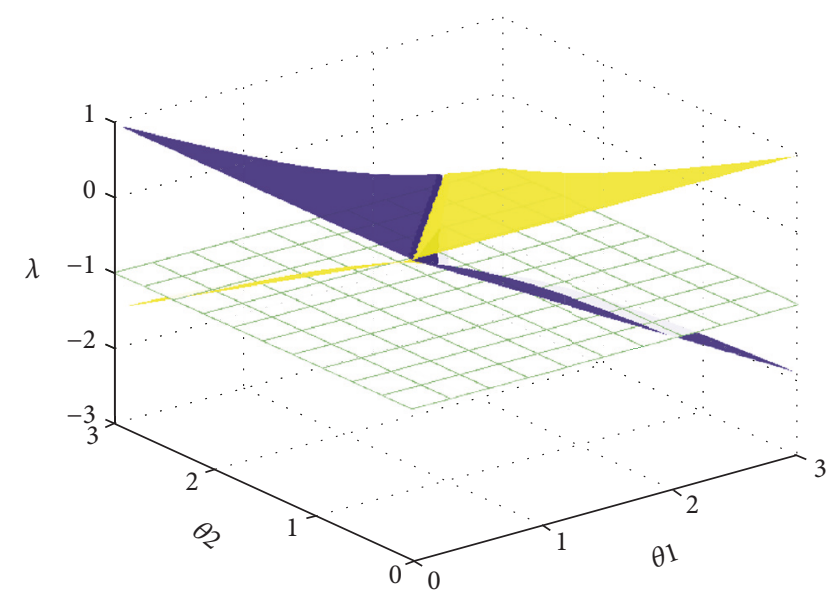

Figure 2: The characteristic root of system (14).

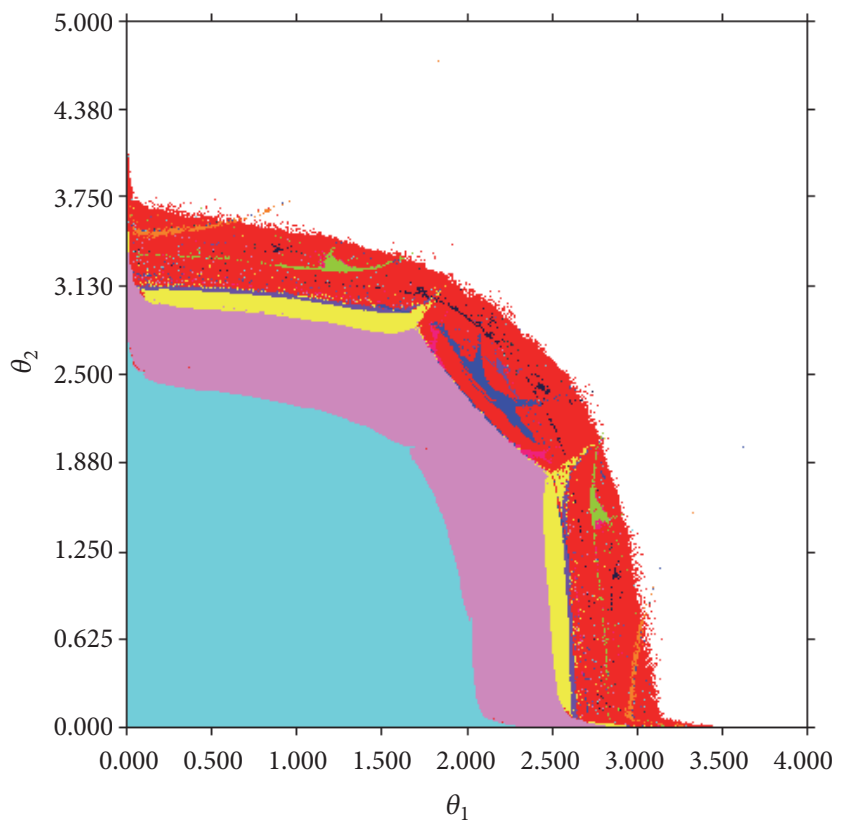

FIGURE 3: The parameter basin plots of system (14).

Different colors in this figure represent the stable region, stable cycles of periods, and chaotic states separately: the light blue range is the stable region, pink range means the stable cycles of period 2, orange range is the stable cycles of period 3 , yellow range is the stable cycles of period 4 , green range is the stable cycles of period 5, dark blue range is the stable cycles of period 6 , cyan range is the stable cycles of period 7 , purple range is the stable cycles of period 8 , red range represents chaos, and white means divergence. If the retail prices are in the white region, one of the retailers is outside the product market, and the market will be oligopolistic market. Through the observation of Figure 3, we find pink, yellow, dark blue, and purple constitute the road from even period cycles to chaos, the road being called the flip bifurcation in discrete dynamical system; meanwhile, orange, green, and cyan constitute the road from odd period cycles to chaos. 


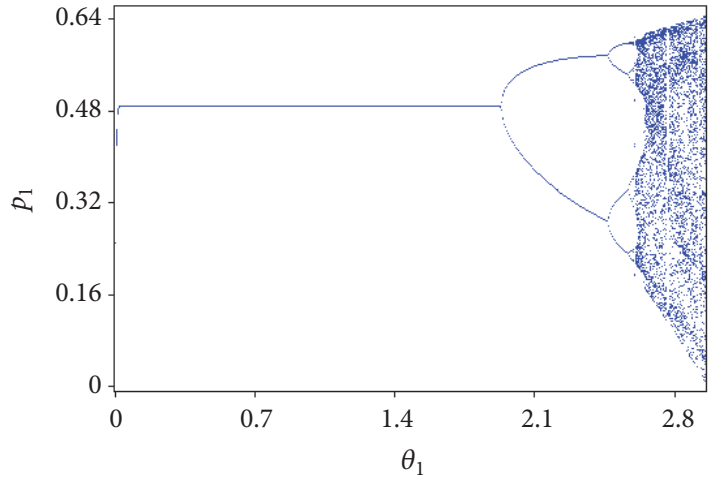

(a) Bifurcation diagram of $p_{1}$ with respect to $\theta_{1}$ when $\theta_{2}=1.2$

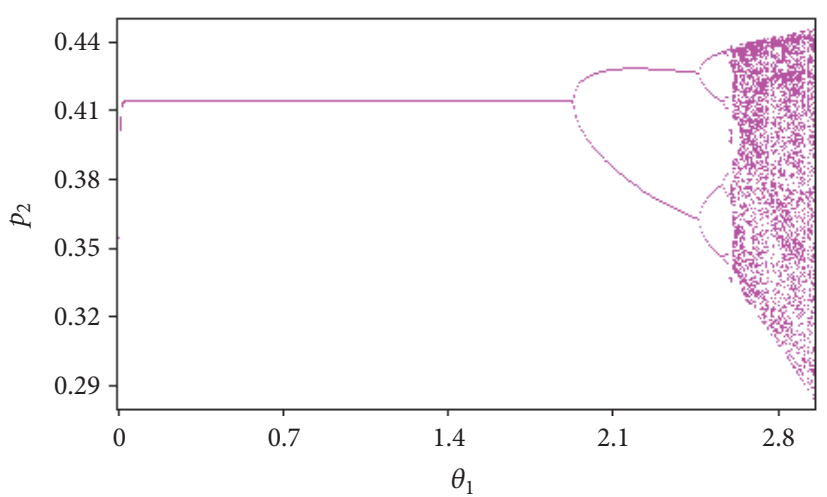

(b) Bifurcation diagram of $p_{2}$ with respect to $\theta_{1}$ when $\theta_{2}=1.2$

FIGURE 4

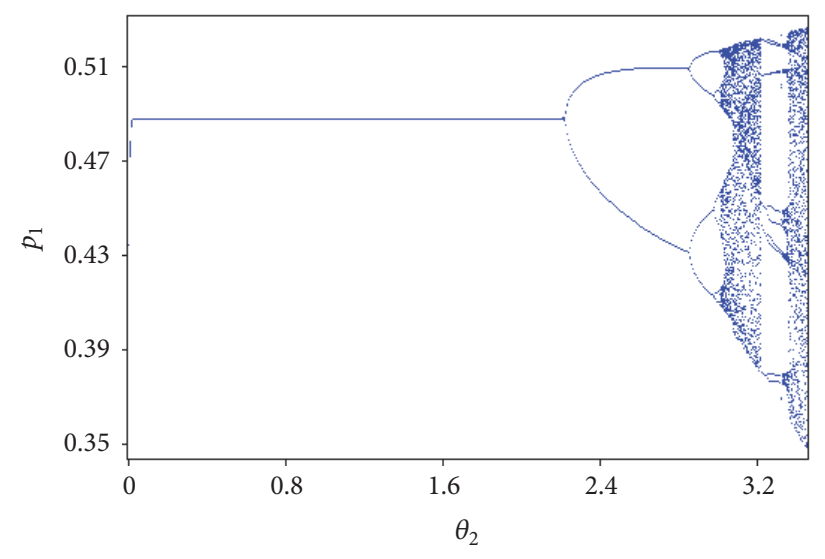

(a) Bifurcation diagram of $p_{1}$ with respect to $\theta_{2}$ when $\theta_{1}=1.2$

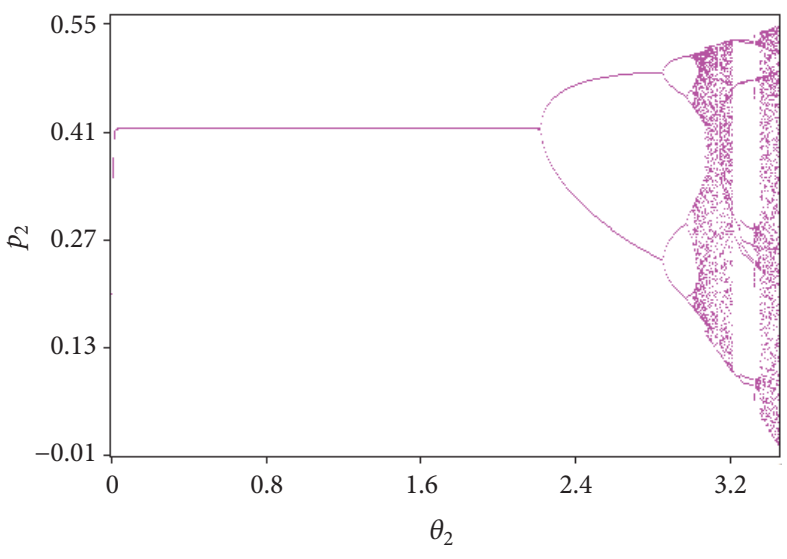

(b) Bifurcation diagram of $p_{2}$ with respect to $\theta_{2}$ when $\theta_{1}=1.2$

FiguRE 5

By observing this figure, we may find the retail price changes from the stable region to the even period cycles and next it gets to chaotic region. This phenomenon is the flip bifurcation, whereby the retailers adjust their own retail price, the system will go from the even period cycles to the chaotic region directly.

Figures 4(a) and 4(b) give the bifurcation diagram of retail prices with respect to $\theta_{1}$ when $\theta_{2}=1.2$. This figure can explain the complex dynamic behavior of the system more intuitively, whereby one of the price adjustment speeds is fixed and the other adjustment speed changes within a certain range. This paper investigates the adjustment speed of retailers' prices firstly by keeping $\theta_{2}$ fixed at 1.2 and $\theta_{1}$ varying from zero to 3. In Figure 4(a), retailer 1's retail price is stable at 0.49 as $\theta_{1}$ vary from zero to 1.95 . Just at this time, the system begins the first bifurcation, while the system runs into stable cycles of period 2. As $\theta_{1}$ increases to 2.47 , the system gets to stable cycles of period 4 . When $\theta_{1}$ gets the value of 2.58 , retail 1's price goes into stable cycles of period 8 . After that, the system falls into a chaotic state.

Figure 4(b) depicts the bifurcation diagram of $p_{2}$ with respect to $\theta_{1}$ when $\theta_{2}=1.2$. The bifurcation points of this figure are completely the same as the bifurcation points in Figure 4(a). However, what is different from Figure 4(a) is the value of retail price. Retailer 2's retail price is stable at 0.415 as $\theta_{1}$ vary from zero to 1.95 . Next, $p_{2}$ gets to cycles of periods 2 , 4 , and 8 in sequence. In the end, $p_{2}$ also falls into chaos.

Figures 5(a) and 5(b) describe the bifurcation behavior of retail prices when $\theta_{2}$ increases gradually and $\theta_{1}$ keeps the fixed value 1.2, which is the same as Figure 4; this shows the complex dynamic behavior of retail price considering the price adjustment speed of retailer 2 varying from zero to 3.5 . In Figure 5(a), as $\theta_{2}$ is small and less than 2.22; the retail price of retailer 1 keeps a fixed number of 0.488 . After that, the retail price falls into the stable cycles of period 2; when $\theta_{2}$ increases to 2.85 , the retail price falls into the stable cycles of period 4 ; then when $\theta_{2}$ goes to 2.98 , the retail price falls into the stable cycles of period 8; and so forth. After the system passes through multiple iterations, it will turn into chaos, which will not be expected to appear.

Analogously, the complex dynamic behavior of retail price 2 considering the price adjustment speed of retailer 2 varying from zero to 3.5 will be shown in Figure 5(b). Firstly, retailer price 2 is stable at 0.414 when $\theta_{2}$ is at $[0,2.22]$. Then the system turns into bifurcation and chaos state orderly. It is worth noting that the stable price of retailer 2 is less than that of retailer 1, which means retailer 2 may possess more market share. This phenomenon is not conducive to retailer 1 . And 


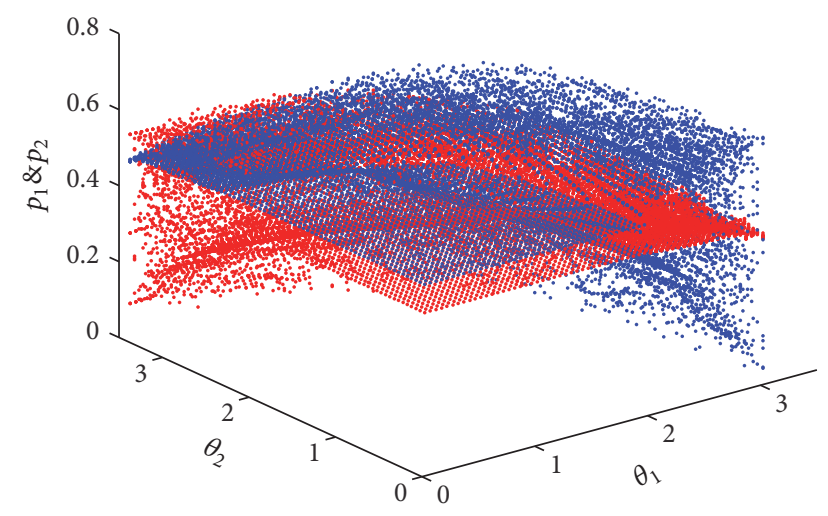

Figure 6: 3D bifurcation diagram of $p_{1}$ and $p_{2}$.

retailer 1 must take measures to decrease its own retail price to win more market demand.

Through the analysis of Figures 4 and 5, we find that relatively small price adjustment speed may maintain the system at stable state. Figure 6 shows the stability of the system from a three-dimensional perspective. With the price adjustment speed gradually increasing, the price system gets unstable and finally becomes chaotic. Hence, from the point of view of management, the retailer should choose a relatively reasonable adjustment speed to alter the retail price in each decision unit.

3.3. The Largest Lyapunov Exponent. The largest Lyapunov exponent (LLE) is another way to make clear the complex dynamic characteristics of the system. And the LLE represents the extreme sensitivity to initial value of the system vividly that two of the same initial value generated in the trajectory separate according to index methods with the passage of time. As we want to judge whether the chaotic phenomenon exists in the system, we just need to observe the LLE intuitively. If the LLE is more than zero, it means that the differences of the initial value increase with exponential form after periods of iteration; that is, the system falls into chaotic region. On the contrary, if the LLE is less than zero, it means that the system is in stable state, while the system is not initially sensitive and keeps a fixed value all the time. When the LLE equals zero, the system is periodic and quasiperiodic. The expression of LLE is as follows:

$$
\lambda=\lim _{n \rightarrow \infty} \frac{1}{n} \sum_{n=0}^{n-1} \ln \left|\frac{d f\left(x_{n}, \mu\right)}{d x}\right| .
$$

We used MATLAB to simulate Figures 7(a) and 7(b). Figures $7(a)$ and $7(b)$ explore the LLE with the increase of price adjustment speed. The system acts out the complex dynamic behavior as the price adjustment speed changes. In Figure $7(\mathrm{a})$, when $\theta_{1}$ is in $[0,1.95]$, the LLE is less than zero and the system is in stable state; while $\theta_{1}$ is in $[1.95,2.6]$, the LLE is equal to zero and the system is in bifurcation region; when $\theta_{1}$ is more than 2.6, the LLE is more than zero and the system is in chaotic region. Figure 7(b) shows the LLE with respect to $\theta_{2}$, and it has the same changing process with $\theta_{1}$. Figure 7 accounts for the state of the dynamic system more intuitively; meanwhile, the bifurcation point and the chaos point in Figure 7 are in consistent with the bifurcation diagrams.

3.4. The Entropy. Entropy is an important quantity to characterize chaotic systems. In different types of dynamic systems, the entropy values are different. Entropy values can be used to distinguish between regular motion, chaotic motion, and random motion. In the random motion system, the entropy is unbounded; in the regular motion system, the entropy is zero; in the chaotic motion system, the entropy is greater than zero. The greater the entropy, the greater the rate of loss of information, the greater the degree of chaos in the system, or the more complex the system.

It can be seen from Figure 8 that as the system progressively enters chaos, the entropy of the system increases rapidly from zero. The law of change is also the same as the change of bifurcation and maximum Lyapunov exponent.

3.5. The Chaotic Attractor. The chaotic attractor investigates the chaotic characteristics of the system and the chaotic attractors will be given in Figures 9(a), 9(b), and 9(c), while the price adjustment speeds are in stable region and chaotic region, respectively. Strange attractor is the joint action's product of overall stability and local instability. All the movement outside the attractor will finally converge to the chaotic attractor. Meanwhile the movement inside the attractor is instable. If the attractor is a fixed point, the system is in stable state. On the contrary, when the attractor is not a fixed point and period cycle, the system is in chaos.

In Figure 9(a), we judged on the parameter basin plots, bifurcation diagram, the largest Lyapunov exponent, and entropy of system; when $\theta_{1}$ and $\theta_{2}$ equal 1.2, they are all in stable states, and at this moment the attractor is a fixed point.

From the parameter basin plots, bifurcation diagram, the largest Lyapunov exponent, and entropy of system, we may see that the systems are in chaotic states while $\theta_{1}=2.8$, $\theta_{2}=1.2$ and $\theta_{1}=1.2, \theta_{2}=3.2$. Hence, the attractors expand to a big area, and the system begins to do limit movement in Figures 9(b) and 9(c). Then the attractors turn into chaotic attractors. Just now, the system becomes complex and the dynamic characteristics of the system are more obviously.

3.6. Time Domain Response. The time domain response depicts the changing process of the price data with the increase of time, which is arranged by the whole time index. There are different shapes for the time domain response. Figures 10(a), 10(b), and 10(c) describe the time domain responses of the system when the price adjustment speeds are in stable region and chaotic region, respectively. In Figure 10, blue line represents the retail price of retailer 1 , and red line represents the retailer price of retailer 2 .

In Figure $10(\mathrm{a}), \theta_{1}$ and $\theta_{2}$ equal 1.2. The price adjustment speeds are all in stable states. Then the two retail price fix at the equilibrium point $E^{*}(0.488,0.414)$, and two retail price will not change as the time changes. It is the same as Figure 9; we set $\theta_{1}=2.8, \theta_{2}=1.2$, and $\theta_{1}=1.2, \theta_{2}=3.2$ in Figures $10(\mathrm{~b})$ and 10(c). In Figure 10(b), while $\theta_{1}$ is in stable region and 


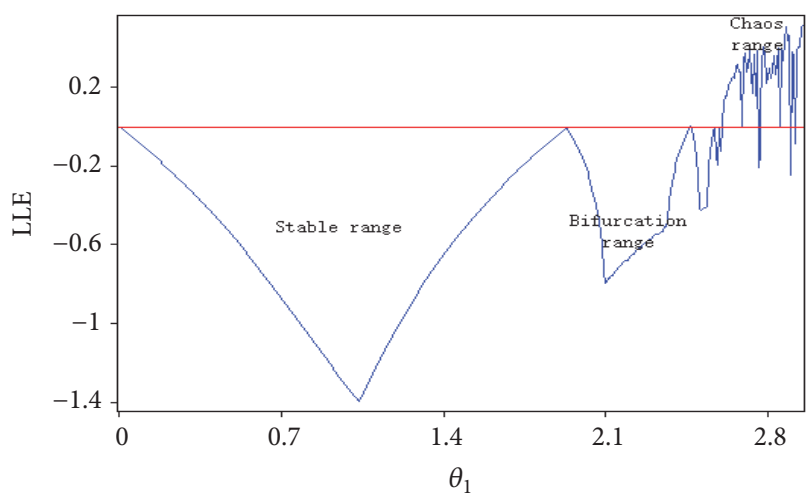

(a) The largest Lyapunov exponent of system with respect to $\theta_{1}$ when $\theta_{2}=$ 1.2

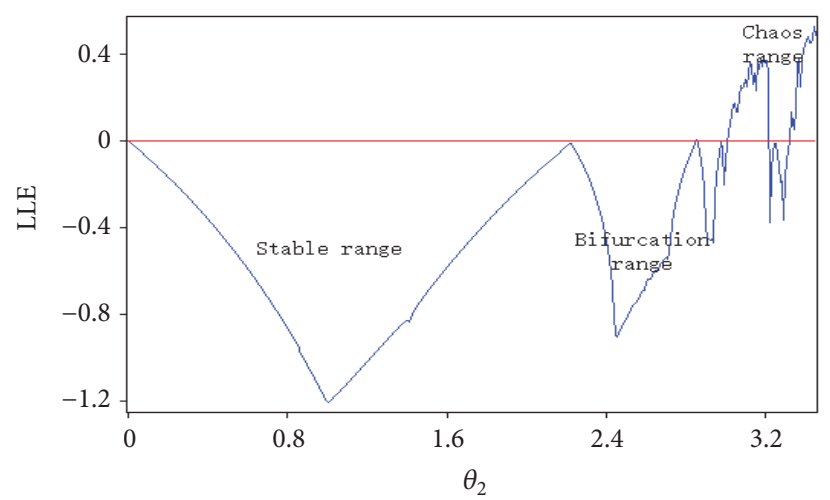

(b) The largest Lyapunov exponent of system with respect to $\theta_{2}$ when $\theta_{1}=$ 1.2

Figure 7

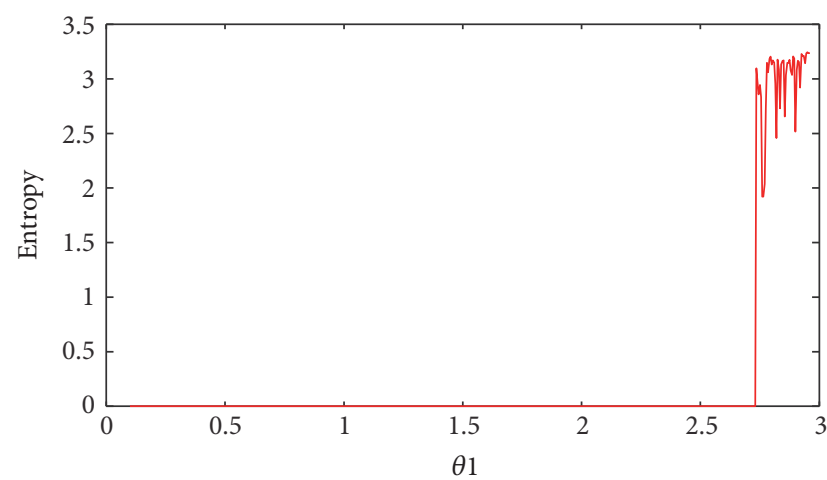

(a) The entropy of system with respect to $\theta_{1}$ when $\theta_{2}=1.2$

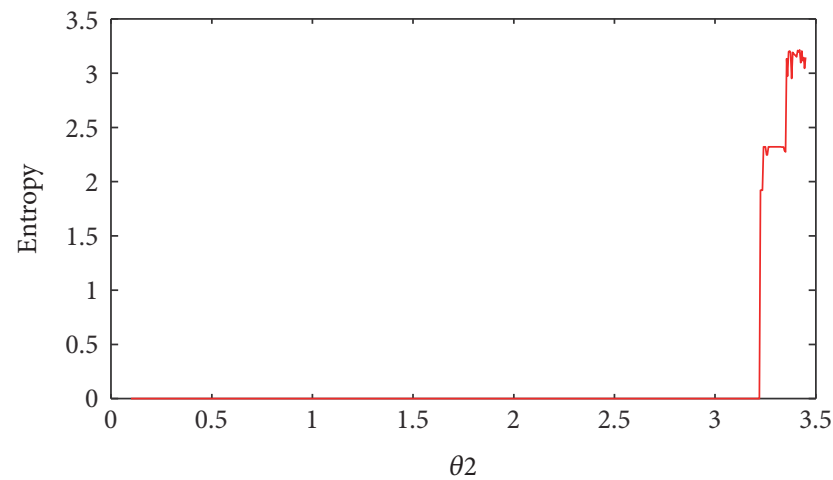

(b) The entropy of system with respect to $\theta_{2}$ when $\theta_{1}=1.2$

FIGURE 8

$\theta_{2}$ is in chaotic area, the fluctuation of blue line is obviously big compared to that of the red line, and the red line just tends to the value 0.36 . Uniformly in Figure 10 (c), the fluctuation of blue line is obviously small compared to that of the red line, and the blue line just tends to the value 0.45 as $\theta_{2}$ is in stable region and $\theta_{1}$ is in chaotic region. This phenomenon shows that when the price adjustment speed is in stable state, the time domain response is smooth. On the contrary, the time domain response will be in big fluctuation while the price adjustment speed is in chaotic state.

\section{Chaos Control}

With the findings of sections above, we come to the conclusion that if the adjustment speeds of the retail prices are in chaotic region, the system will be complex, and the manager cannot make decision in time that phenomenon is not expected to appear in the product market. Therefore, we should take measure to expand the stable region and control the chaos further. From the management point of view, the market is sharply fluctuating while the adjustment speeds of the retail prices expand from the stable region to chaotic region; hence the adjustment speeds of the retail prices must be in stable region so as to keep the market smooth. Then the chaos control method becomes necessary.
Here, we employ the widely used control method, that is, parameter adjustment control method to control the chaotic phenomenon. Ma and $\mathrm{Li}$ [23] adopted this kind of method to control the complex dynamic behavior of the pricing game models in a risk-averse supply chain, and the chaos has been controlled perfectly. Hence, we also adopt parameter adjustment control method so as to solve this problem in this section. The manager may control the chaotic behavior through introducing the control parameter $u$, and we set $u=$ 0.6 as Ma et al. [24] have conducted the chaos control with setting the control parameter as 0.6. The other parameters employ the values set in the sections above. After that, the stable range and the bifurcation diagram will be given to account for the state of the system. With the parameter adjustment control, the system will be

$$
\begin{aligned}
& p_{1}(t+1)=(1-u)\left(p_{1}(t)+\theta_{1} p_{1}(t)\left(\left(1-g_{1}\right) a_{0,1}\right.\right. \\
& +g_{1} f_{1}-2 b_{1} p_{1}+b_{2} p_{2}+k_{1} v_{1}-k_{2} v_{2}+b_{1} w \\
& \left.\left.\quad+b_{1} \eta_{1} \frac{v_{1}^{2}}{2}\right)\right)+u p_{1}(t)
\end{aligned}
$$




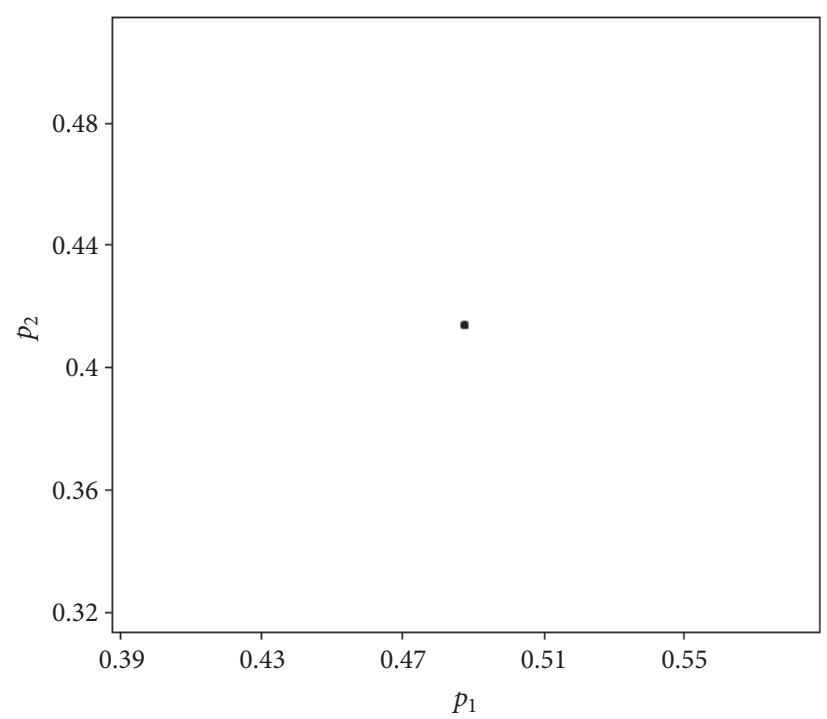

(a) The chaotic attractor of system when $\theta_{1}=\theta_{2}=1.2$

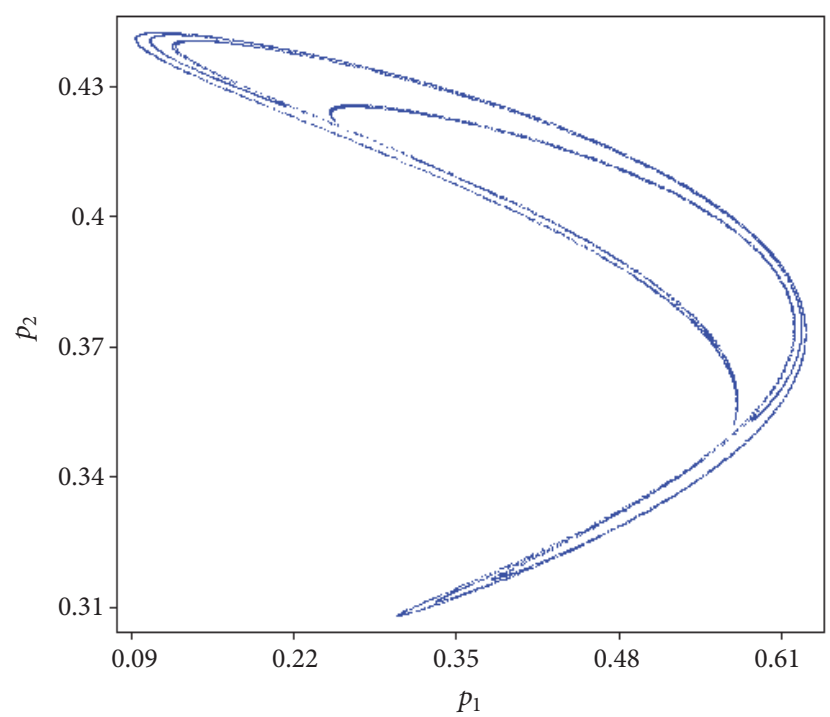

(b) The chaotic attractor of system when $\theta_{1}=2.8, \theta_{2}=1.2$

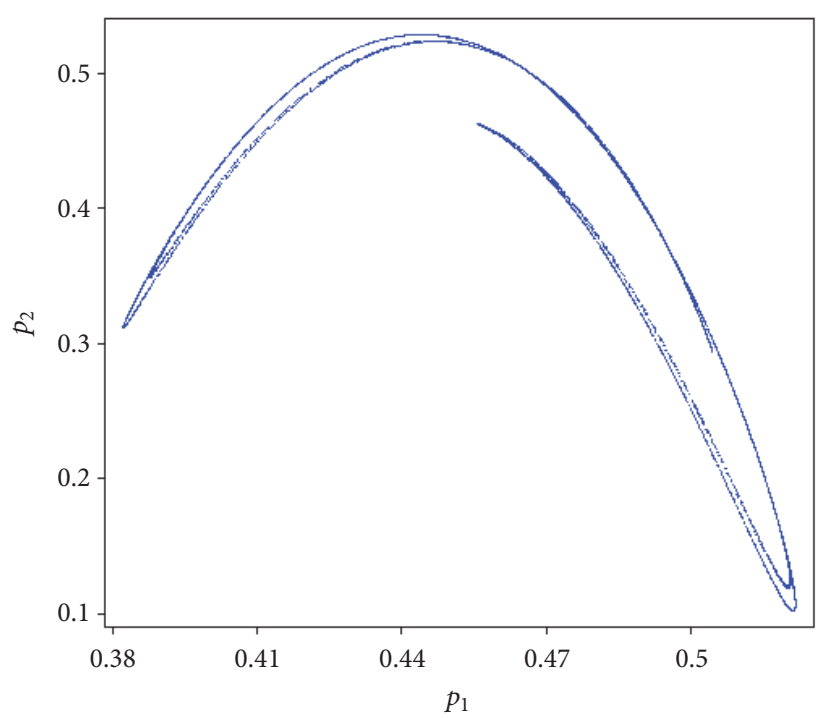

(c) The chaotic attractor of system when $\theta_{1}=1.2, \theta_{2}=3.2$

FIGURE 9

$$
\begin{aligned}
& p_{2}(t+1)=(1-u)\left(p_{2}(t)+\theta_{2} p_{2}(t)\left(\left(1-g_{2}\right) a_{0,2}\right.\right. \\
& +g_{2} f_{2}-2 b_{1} p_{2}+b_{2} p_{1}+k_{1} v_{2}-k_{2} v_{1}+b_{1} w \\
& \left.\left.+b_{1} \eta_{2} \frac{v_{2}^{2}}{2}\right)\right)+u p_{2}(t) .
\end{aligned}
$$

Figure 11 depicts the stable region after having been controlled by the control parameter. Compared to the stable region of system (14), the stable region of system (20) increases obviously, which means a relative large price adjustment speed will not make the system run into chaos. This is helpful for managers to adjust the retail price with a more range.
The complex dynamic behavior of system (20) has been investigated in Figures 12 and 13. The first bifurcation point of the system is big compared to that before controlling, the value of which is 5 , and it is bigger than value (1.95) of first bifurcation point in system (14) in Figure 9 depicting the bifurcation diagram of $p$ with respect to $\theta_{1}$ when $\theta_{2}=1.2$. Figure 10 shows the bifurcation diagram of $p$ with respect to $\theta_{2}$ when $\theta_{1}=1.2$. It is similar to the phenomenon in Figure 12 that the first bifurcation point of the system is big compared to that before controlling. The first bifurcation point expands to 5.92 that the stable region of system (20) is enlarged. Hence, the managers will make decisions relatively simple.

Bifurcation diagram of $p$ when the control parameter $u$ varies from 0 to 1 is given in Figure 14. When $u$ takes the value of zero, system (20) will be the same as system (14), and then the system is chaotic. With the increase of $u$, the 


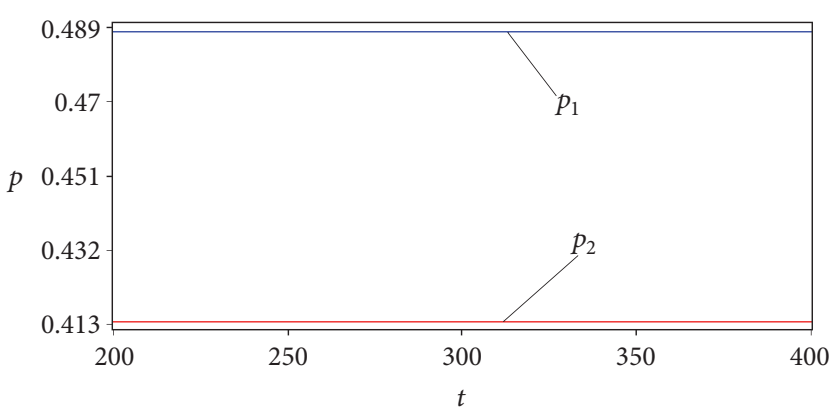

(a) The time domain response of system when $\theta_{1}=\theta_{2}=1.2$

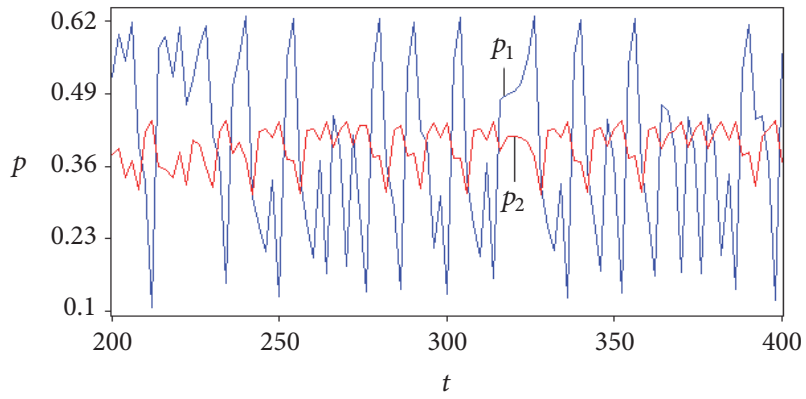

(b) The time domain response of system when $\theta_{1}=2.8, \theta_{2}=1.2$

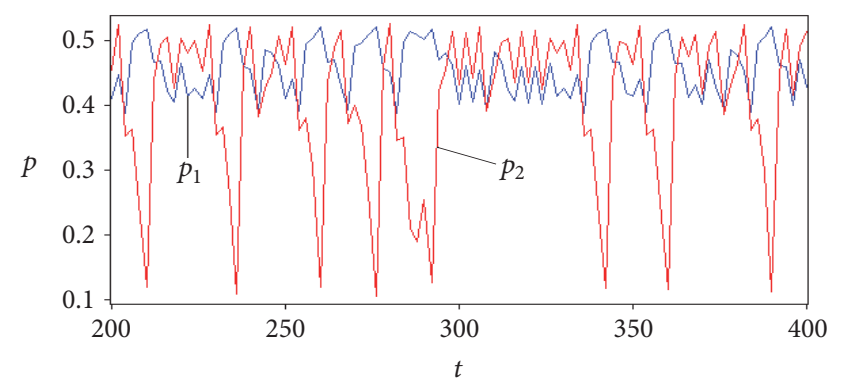

(c) The time domain response of system when $\theta_{1}=1.2, \theta_{2}=3.2$

FIGURE 10

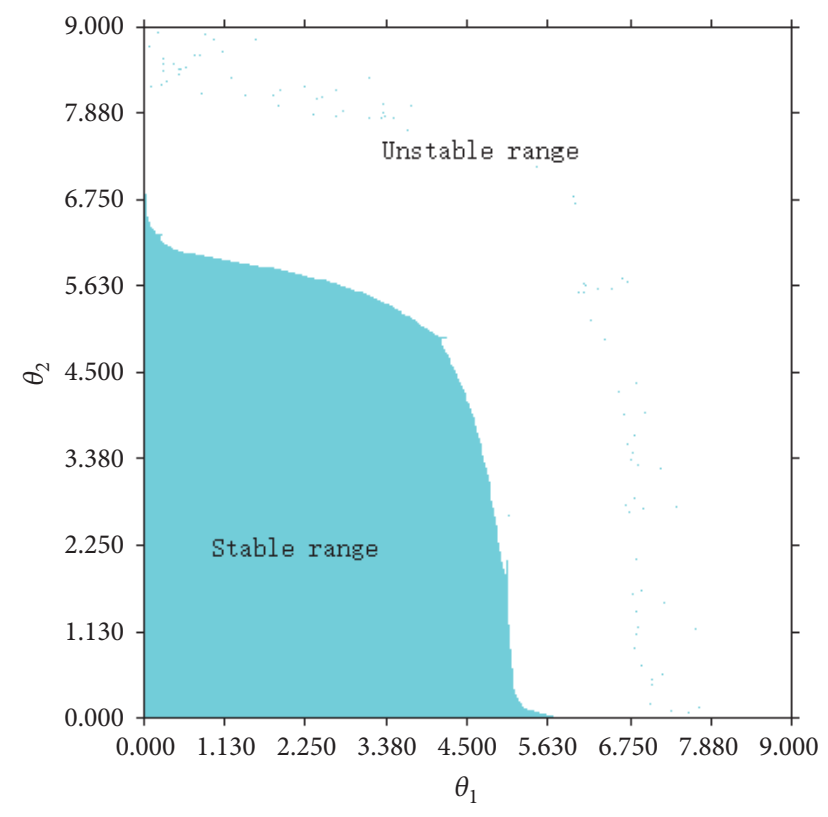

FIGURE 11: The stable range of system (20).

system changes from the chaotic region to the bifurcation region and finally falls into the stable region, which means the chaos behavior has been controlled completely.

\section{Conclusion}

Previous researches have explored the price fluctuation with price and demand game model in the supply chain

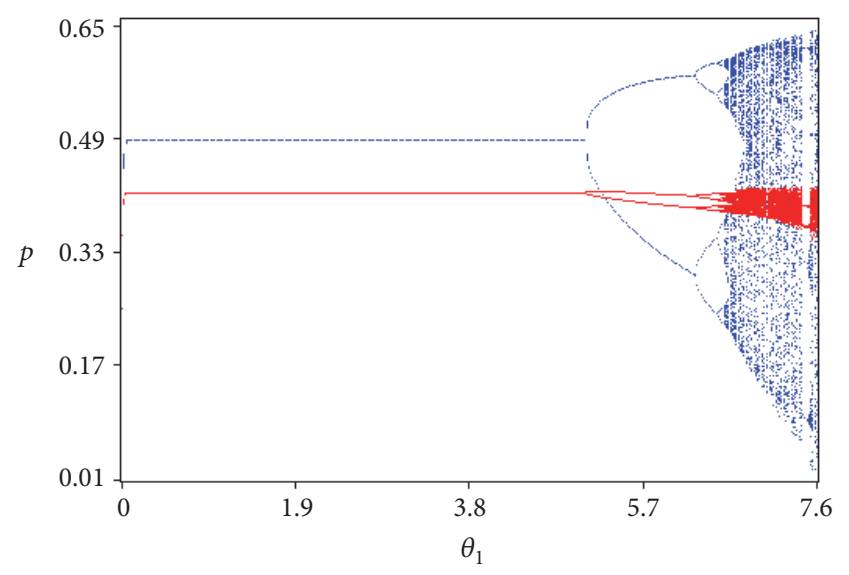

FIGURE 12: Bifurcation diagram of $p$ with respect to $\theta_{1}$ when $\theta_{2}=$ 1.2 .

management. However the retailers' service level has not been involved in the basic demand model. This paper depicts a modified Bertrand duopoly model based on the stochastic demand and the retailer's service level which influences the market demand decided by customers' preference, while the market demand is stochastic in this model. How the price adjustment speed affects the stability of the supply chain system with respect to service level and stochastic demand has been studied in this paper. The dynamic behavior of the system is researched by simulation and the stability domain and the bifurcation phenomenon are shown clearly. The largest Lyapunov exponent, the chaotic attractor, and the time series are also given to confirm the chaotic characteristic of the system. 


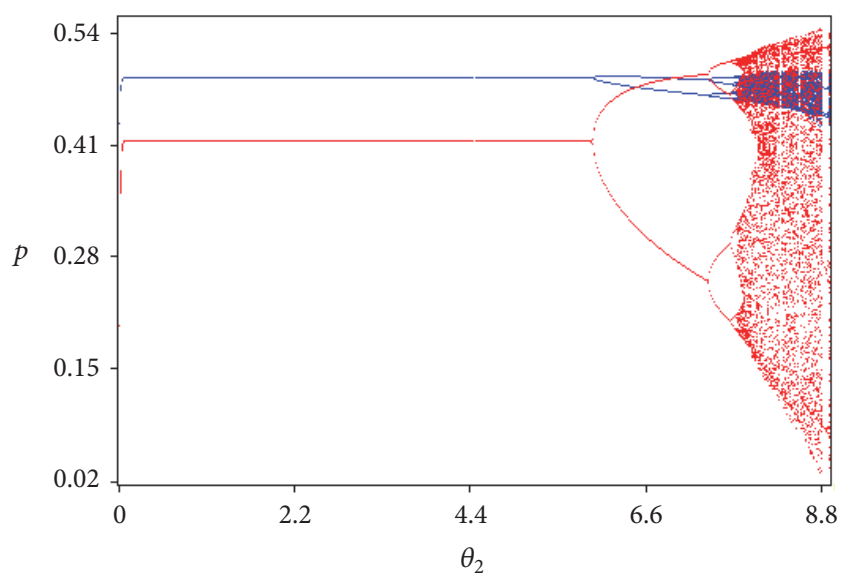

FIGURE 13: Bifurcation diagram of $p$ with respect to $\theta_{2}$ when $\theta_{1}=1.2$.

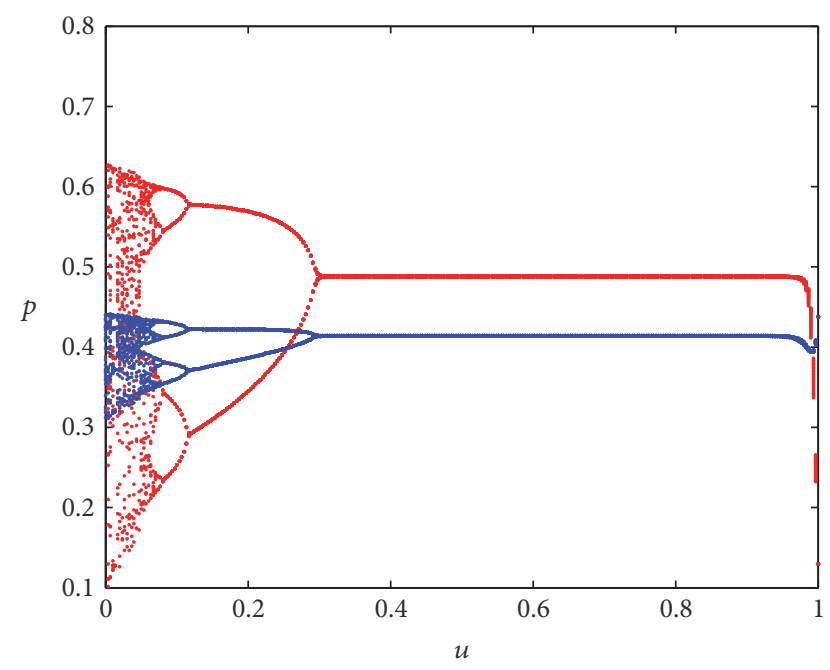

FIGURE 14: Bifurcation diagram of $p$ when $u$ varies from 0 to 1 .

We come to the conclusion that (1) with the price adjustment speed gradually increasing, the price system gets unstable and finally becomes chaotic; (2) a relatively small price adjustment speed may maintain the system at stable state; (3) chaos can be controlled completely with the parameter control method. This chaotic phenomenon will perturb the product market. Hence, the conclusion makes significant contribution to the system, referring to the price fluctuation based on the service level and stochastic demand.

In spite of the contribution that this paper has offered to the managers, some limitations still exist in this paper. Firstly, the supply chain only contains two retailers; in order for this study to be more close to the reality and be used in more scales of enterprises, we may study the dynamic game behavior in the three-oligarch product market. Secondly, this paper only does the numerical simulation, while there are no real data to support the conclusion of the paper. Hence, some real data should be collected to identify the conclusion.

\section{Conflicts of Interest}

The authors declare no conflicts of interest.

\section{Authors' Contributions}

Weiya Di and Junhai Ma built the supply chain model; Junhai $\mathrm{Ma}$ provided economic interpretation; Weiya Di carried out numerical simulation; Hao Ren performed mathematical derivation; the authors wrote this research manuscript together. All authors have read and approved the final manuscript.

\section{Acknowledgments}

The research was supported by the National Natural Science Foundation of China (71571131).

\section{References}

[1] T. Xiao and D. Yang, "Price and service competition of supply chains with risk-averse retailers under demand uncertainty," International Journal of Production Economics, vol. 114, no. 1, pp. 187-200, 2008.

[2] R. Yan and Z. Pei, "Retail services and firm profit in a dualchannel market," Journal of Retailing and Consumer Services, vol. 16, no. 4, pp. 306-314, 2009.

[3] J. M. Hall, P. K. Kopalle, and A. Krishna, "Retailer Dynamic Pricing and Ordering Decisions: Category Management versus Brand-by-Brand Approaches," Journal of Retailing, vol. 86, no. 2, pp. 172-183, 2010.

[4] A. Ghosh and M. Mitra, "Comparing Bertrand and Cournot in mixed markets," Economics Letters, vol. 109, no. 2, pp. 72-74, 2010.

[5] C. H. Tremblay and V. J. Tremblay, "The Cournot-Bertrand model and the degree of product differentiation," Economics Letters, vol. 111, no. 3, pp. 233-235, 2011.

[6] M. A. Sieke, R. W. Seifert, and U. W. Thonemann, "Designing service level contracts for supply chain coordination," Production and Operations Management, vol. 21, no. 4, pp. 698-714, 2012.

[7] J. Ma and J. Zhang, "Price game and chaos control among three oligarchs with different rationalities in property insurance market," Chaos. An Interdisciplinary Journal of Nonlinear Science, vol. 22, no. 4, Article ID 043120, 043120, 13 pages, 2012.

[8] A. K. Naimzada and F. Tramontana, "Dynamic properties of a Cournot-Bertrand duopoly game with differentiated products," Economic Modelling, vol. 29, no. 4, pp. 1436-1439, 2012.

[9] A. A. Elsadany, "Competition analysis of a triopoly game with bounded rationality," Chaos, Solitons and Fractals, vol. 45, no. 11, pp. 1343-1348, 2012.

[10] J. K. Jha and K. Shanker, "Single-vendor multi-buyer integrated production-inventory model with controllable lead time and service level constraints," Applied Mathematical Modelling. Simulation and Computation for Engineering and Environmental Systems, vol. 37, no. 4, pp. 1753-1767, 2013.

[11] H. Wang and J. Ma, "Complexity analysis of a cournotbertrand duopoly game model with limited information," Discrete Dynamics in Nature and Society, vol. 2013, Article ID 287371, 2013 
[12] A. Mahmoodi and K. Eshghi, "Price competition in duopoly supply chains with stochastic demand," Journal of Manufacturing Systems, vol. 33, no. 4, pp. 604-612, 2014.

[13] E. Ahmed, A. A. Elsadany, and T. Puu, "On Bertrand duopoly game with differentiated goods," Applied Mathematics and Computation, vol. 251, pp. 169-179, 2015.

[14] Y. Kawabata and Y. Takarada, "Welfare implications of free trade agreements under Bertrand and Cournot competition with product differentiation," International Economics, vol. 142, pp. 4-14, 2015.

[15] S. Brianzoni, L. Gori, and E. Michetti, "Dynamics of a Bertrand duopoly with differentiated products and nonlinear costs: Analysis, comparisons and new evidences," Chaos, Solitons and Fractals, vol. 79, pp. 191-203, 2015.

[16] W. Liu and Y. Wang, "Quality control game model in logistics service supply chain based on different combinations of risk attitude," International Journal of Production Economics, vol. 161, pp. 181-191, 2015.

[17] Y. Fang and B. Shou, "Managing supply uncertainty under supply chain Cournot competition," European Journal of Operational Research, vol. 243, no. 1, pp. 156-176, 2015.

[18] A. Esmaeilzadeh and A. A. Taleizadeh, "Pricing in a twoechelon supply chain with different market powers: Game theory approaches," Journal of Industrial Engineering International, vol. 12, no. 1, pp. 119-135, 2016.

[19] J. Ma and Z. Guo, "The influence of information on the stability of a dynamic Bertrand game," Communications in Nonlinear Science and Numerical Simulation, vol. 30, no. 1-3, pp. 32-44, 2016.

[20] Q.-H. Li and B. Li, "Dual-channel supply chain equilibrium problems regarding retail services and fairness concerns," Applied Mathematical Modelling. Simulation and Computation for Engineering and Environmental Systems, vol. 40, no. 15-16, pp. 7349-7367, 2016.

[21] M. Protopappa-Sieke, M. A. Sieke, and U. W. Thonemann, "Optimal two-period inventory allocation under multiple service level contracts," European Journal of Operational Research, vol. 252, no. 1, pp. 145-155, 2016.

[22] L. Li, "Information sharing in a supply chain with horizontal competition," Management Science, vol. 48, no. 9, pp. 1196-1212, 2002.

[23] J. Ma and Q. Li, "The complex dynamics of BertrandStackelberg pricing models in a risk-averse supply chain," Discrete Dynamics in Nature and Society, vol. 2014, Article ID 749769, 14 pages, 2014.

[24] J. Ma, X. Ma, and W. Lou, "Analysis of the Complexity Entropy and Chaos Control of the Bullwhip Effect Considering Price of Evolutionary Game between Two Retailers," Entropy, vol. 18, no. 11, p. 416, 2016. 


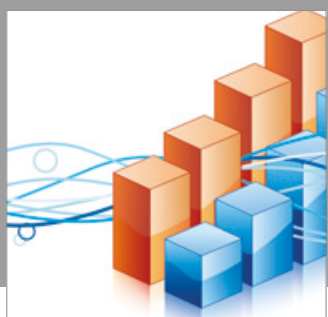

Advances in

Operations Research

vatersals

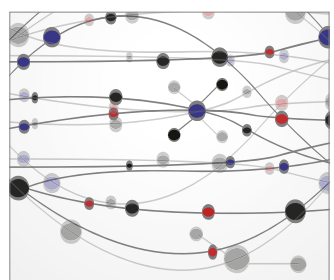

\section{The Scientific} World Journal
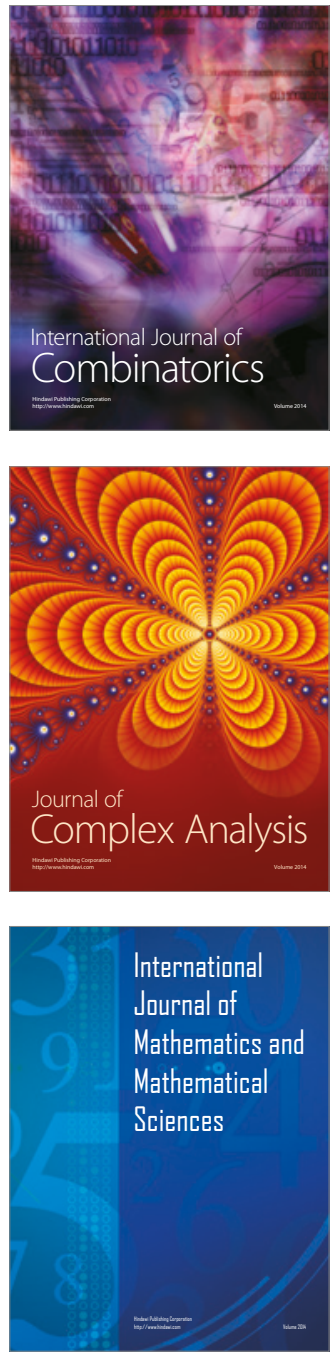
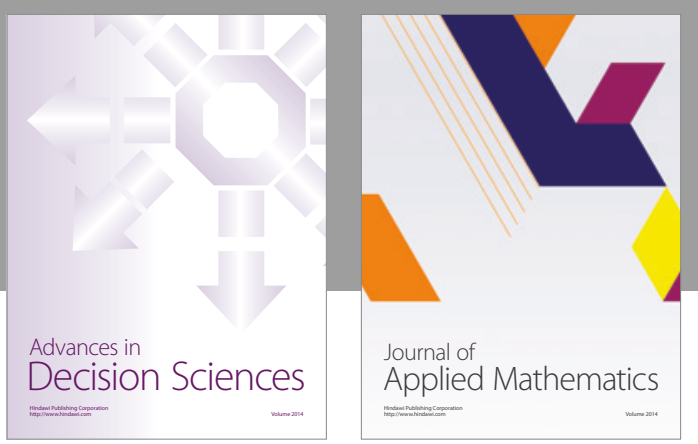

Algebra

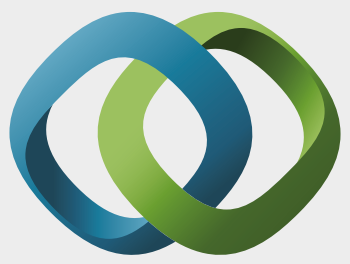

\section{Hindawi}

Submit your manuscripts at

https://www.hindawi.com
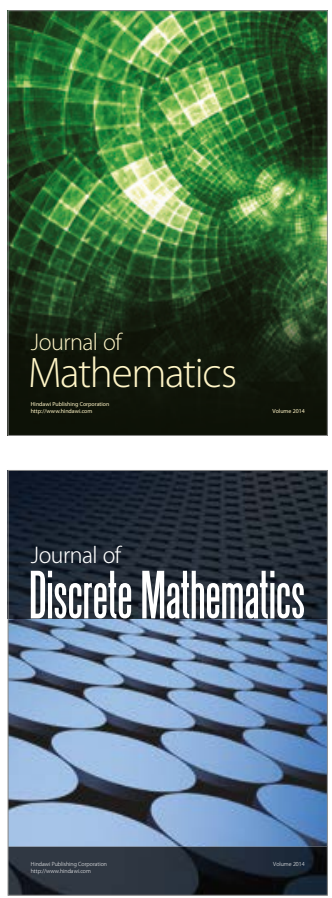

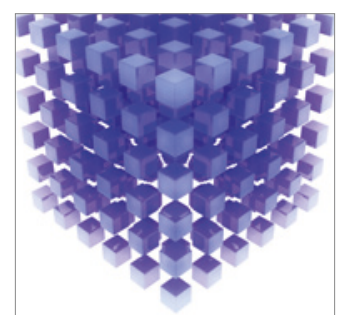

Mathematical Problems in Engineering
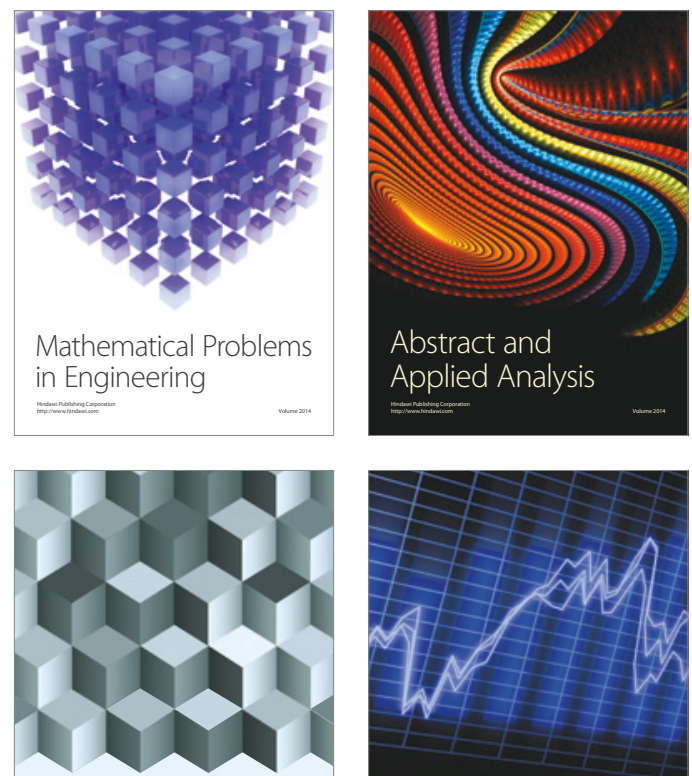

Journal of

Function Spaces

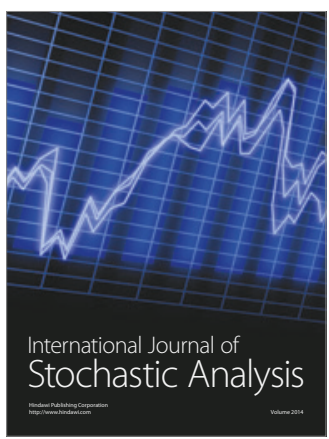

Probability and Statistics
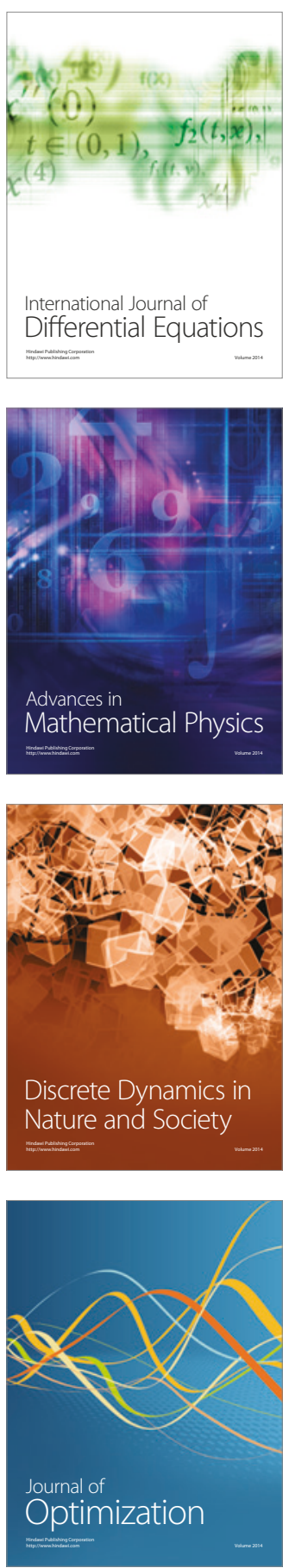